\title{
Smoking Patterns, Depression, and Sociodemographic Variables Among Flemish Women During Pregnancy and the Postpartum Period
}

\author{
Katrien S. De Wilde $\mathbf{v}$ Leen C. Trommelmans $\boldsymbol{\nabla}$ Hans H. Laevens $\boldsymbol{\nabla}$ Lea R. Maes \\ Marleen Temmerman $\mathbf{v}$ Hedwig L. Boudrez
}

Background: Relationships among feelings of depression, smoking behavior, and educational level during pregnancy have been documented. Feelings of depression may contribute to persistent smoking during pregnancy. No longitudinal studies assessing feelings of depression in women with different antepartum and postpartum smoking patterns are available.

- Objectives: The aim was to determine relationships between depressive symptoms, sociodemographic characteristics, and smoking pattern during and after pregnancy.

- Methods: An observational, prospective, noninterventional study was conducted. Data were collected during two stages of pregnancy (T0: $<16$ weeks and T1: 32-34 weeks) and postpartum (T2: $>6$ weeks) in 523 Flemish women. Feelings of depression (measured using the Beck Depression Inventory $[\mathrm{BDI}]$ ), smoking behavior, and sociodemographic variables were analyzed using a general linear mixed model implemented in SAS Proc MIXED.

- Results: Smokers and initial smokers reported significantly more depressive symptoms at all time points compared with recent ex-smokers, nonsmokers, and initial nonsmokers $(p<$ .001). The three-way interaction among time point, smoking pattern, and educational level was significant $(p=.02)$. Evolution of mean BDI over time differed by educational level. Among participants with a secondary school certificate or less, differences were observed between smokers and nonsmokers, recent exsmokers and initial nonsmokers, and nonsmokers and initial nonsmokers. Among participants with a college or university degree, no differences were observed.

- Discussion: A wide variety of smoking patterns were observed during pregnancy and early postpartum. Smoking patterns were associated with depression and showed complex interactions with educational level. Assessment and intervention for both smoking and depression are needed throughout the perinatal period to support the health of mothers, their infants, and families.

- Key Words: depression · Iongitudinal studies · pregnancy · prospective studies $\cdot$ smoking
$\mathbf{S}$ moking during pregnancy causes significant fetal and maternal morbidity, including placental abruption, intrauterine growth restriction, preterm birth, low birth weight, stillbirth, and infant death (Levitt, Shaw, Wong, \& Kaczorowski, 2007; Lumley et al., 2009). Postnatal parental smoking is an important risk factor for sudden infant death syndrome, bronchitis, pneumonia, asthma, and middle ear infections (Levitt et al., 2007; Lumley et al., 2009). In Europe, the prevalence of smoking during pregnancy ranges from $7.6 \%$ in the Netherlands (Hoppenbrouwers et al., 2011) to 31\% in Spain (Palma et al., 2007). Relapse rates in postpartum for women who quit during pregnancy fluctuate between $9.5 \%$ and $18.5 \%$ within 3 months (Lauria, Lamberti, \& Grandolfo, 2011); other research shows that $66 \%-80 \%$ are smoking again within 1 year (Pickett, Wilkinson, \& Wakschlag, 2009). In Flanders - the Dutchspeaking part of Belgium - the prevalence of smoking in women is $22.7 \%$ in the year prior to the pregnancy; this decreases to $12.3 \%$ during pregnancy. Three months after delivery, the prevalence is $14.2 \%$ (Hoppenbrouwers et al., 2011).

Depression during pregnancy is associated with a modest but statistically significant risk for preterm birth (Grote et al., 2010), poor health behaviors, preeclampsia, poor pregnancy outcomes, and increased risk of progression to postpartum depression (Bennett, Einarson, Taddio, Koren, \& Einarson, 2004). During pregnancy and in the postpartum period, women experience hormonal fluctuations, which can increase the occurrence of mood disorders (Bennett et al., 2004; Marcus

Katrien S. De Wilde, MSc, Doctoral candidate; Leen C. Trommelmans, PhD, is Staff Member; and Hans H. Laevens, DVM, PhD, is Staff Member, Department of Health, Catholic University College Ghent, Belgium.

Lea R. Maes, PhD, is Professor, Department of Public Health, Faculty of Medicine and Health Sciences, Ghent University, Belgium.

Marleen Temmerman, MD, MPH, PhD, is Professor, Department of Obstetrics and Gynecology, Faculty of Medicine and Health Sciences, Ghent University, Belgium.

Hedwig L. Boudrez, PhD, is Staff Member, Stop-Smoking Clinic, Ghent University, Belgium.

DOI: 10.1097/NNR.0b013e3182a59d96 
\& Heringhausen, 2009). Loss of energy and changes in sleep pattern and appetite may be attributed to pregnancy, but these symptoms might also be signs of depression. The transition to motherhood and corresponding role changes can also influence the mental health of women, especially of primigravidas, who may face problems related to the life circumstances that altered pregnancy and motherhood (Edwards, Galletly, Semmler-Booth, \& Dekker, 2008; Emmanuel \& St John, 2010). The American College of Obstetricians and Gynecologists, therefore, recommends screening for depression during each pregnancy trimester and, if necessary, referral to specialist care (Grote et al., 2010; Lancaster et al., 2010). Research also suggests that prenatal depression is one of the strongest predictors of postpartum depression (Beck, 2001). About $20 \%$ of pregnant women show elevated depressive symptomatology (Marcus, Flynn, Blow, \& Barry, 2003); a few studies suggest that $5 \%-10 \%$ experience a major depressive disorder (Marcus \& Heringhausen, 2009; Melville, Gavin, Guo, Fan, \& Katon, 2010). The prevalence of depression increases during pregnancy (Bennett et al., 2004). No specific data are available from Flanders on depression during pregnancy.

Symptoms of depression may contribute independently to persistent smoking during pregnancy (Scott, Heil, Higgins, Badger, \& Bernstein, 2009). Depressed persons may smoke to immediately improve their sense of well-being or as a quick reward. These responses may make it more difficult for depressed pregnant women to quit smoking (Zhu \& Valbo, 2002). Some research suggests that smokers themselves are convinced that quitting generates feelings of depression and dysphoria arising from nicotine withdrawal (Solomon et al., 2006), although this was not confirmed by other studies (Berlin, Chen, \& Covey, 2010; Kahler, Spillane, Busch, \& Leventhal, 2011). No evidence is available to confirm that quitting smoking during pregnancy increases psychological symptoms in the immediate postwithdrawal period or later in pregnancy (Solomon et al., 2006). Women who quit smoking early in pregnancy and remained abstinent during postpartum reported less depressive symptoms compared with women who continued to smoke (Park et al., 2009; Solomon et al., 2006).

There is a positive association between higher educational level ( $>12$ years of education) and the likelihood of quitting smoking before entering prenatal care. Less educated women ( $\leq 12$ years of education) are more likely to continue to smoke during and after pregnancy (Higgins et al., 2009). The association of educational level with smoking behavior is also present in Flanders: $34.3 \%$ in women with less than 12 years of education are smoking, $19.5 \%$ in women with 12 years of education, and $3.9 \%$ in women with a college or university degree (mean prevalence $12.3 \%$; Hoppenbrouwers et al., 2011).

Lancaster et al. (2010) found a small association between a lower educational level and antepartum depressive symptoms in bivariate studies, but there was no significant association in the multivariate studies.
Lack of social support, especially of partner support, is significantly associated with depressive symptoms during pregnancy (Lancaster et al., 2010). Living with a smoking partner makes it harder for a pregnant woman to quit. Partners are major amplifiers of smoking behavior, both positive and negative, and are key contributors toward the success or failure of the women's smoking cessation efforts (Hauge, Torgersen, \& Vollrath, 2012; Schneider, Huy, Schütz, $\&$ Diehl, 2010).

Relationships between feelings of depression, sociodemographic characteristics, and smoking behavior during pregnancy have been documented (Leung, Gartner, Hall, Lucke, \& Dobson, 2012). So far, however, there have been no longitudinal studies assessing these factors antepartum and postpartum. This study extends previous work in male and nonpregnant populations to women during and after pregnancy.

The aim of this longitudinal study is to obtain insight into the associations between smoking patterns and depressive feelings during pregnancy and postpartum, taking into account several sociodemographic characteristics. The following research questions were formulated:

1. Which patterns of smoking behavior can be observed during and after pregnancy?

2. Which patterns of depression can be observed during and after pregnancy?

3. Is there a relationship between smoking pattern and feelings of depression during and after pregnancy, independent from sociodemographic characteristics?

To answer these questions, pregnant women were asked about their smoking habits, their feelings of depression, and their partners' smoking habits. Answers were assessed in relation to sociodemographic variables: age, educational level, job status, gravidity, and marital status.

\section{Methods}

\section{Design}

The design was observational, prospective, and noninterventional. Data were collected at three points in time: before 16 weeks of pregnancy (T0), between 32 and 34 weeks of pregnancy (T1), and at least 6 weeks postpartum (T2). For determining $\mathrm{T} 0$, the confirmation of the pregnancy by blood analysis and ultrasound and the decreasing chance of spontaneous abortion after 12 weeks were taken into account. T1 was chosen in the third trimester to acquire data covering a large part of pregnancy and to avoid dropouts because of preterm birth. At T2, women had already experienced the challenges of early motherhood and adapted their lifestyles to the newborns. Ethics approval was received from the Ethical Committee of the University Hospital of Ghent. Written informed consent was obtained from respondents, all of whom were assured of confidentiality. 


\section{Sampling}

Recruitment took place between September 2008 and March 2010; data were collected between September 2008 and December 2010. Convenience sampling was used, with a quota for smokers. Because a dropout of respondents could be expected in a longitudinal study, special attention was paid to the recruitment of pregnant smokers. The prevalence of smoking during pregnancy in Belgium is $12.3 \%$. A total of 627 respondents were recruited, of which 102 were smokers $(16.3 \%)$ at T0.

Respondents were recruited through the following sources:

1. The research team was available during pregnancy consultations in two hospitals (University Hospital Ghent, AZ Nikolaas at Sint-Niklaas). One hundred twenty-five women were recruited in Ghent, and 140 women in Sint-Niklaas (total 265 women). At these locations, all participating women were invited for a CO measurement using the Smokerlyzer Micro (Bedfont Scientific Ltd.), a biochemical validation of the smoking status (Usmani, Craig, Shipton, \& Tappin, 2008). CO levels were defined in 257 women; eight respondents could not be tested because of lack of time. All respondents exhibiting CO levels of $\geq 6$ ppm were considered as smokers and categorized accordingly, even if they reported to be nonsmoker $(n=2)$. Questionnaires were answered by telephone, except at T0: if there was the possibility the first questionnaire was filled out at the moment of recruitment.

2. A convenience sample of 12 gynecologists and 10 midwives agreed to participate in the project. Through their mediation, 370 women were recruited and contacted by telephone. These respondents answered the questionnaires by telephone without having a $\mathrm{CO}$ measurement.

CO measurement was used to validate the self-reported smoking status in 257 of 627 respondents (42.7\%). The cutoff point normally applied in smoking cessation studies in nonpregnant respondents is $10 \mathrm{ppm}$. Because the metabolism of pregnant women is accelerated, ending in faster elimination of $\mathrm{CO}$ particles in the body, $10 \mathrm{ppm}$ may not give an accurate representation of their smoking status. There is no consensus concerning the correct cutoff point in pregnant smokers. Several limits have been used: 8 ppm (Christensen et al., 2004), 7 ppm (McGowan et al., 2010), 6 ppm (Secker-Walker, Vacek, Flynn, \& Meads, 1997), 4 ppm (Higgins et al., 2007), and 3 ppm (Usmani et al., 2008). A study by Benowitz et al. (2002) suggested that a cutoff point of $>7 \mathrm{ppm}$ is too high and misses $36 \%$ of the self-reported smokers: therefore, $6 \mathrm{ppm}$ was used as the cutoff point.

Research has shown a very low rate of false reporting of smoking cessation in impersonal telephone interviews (Crittenden, Manfredi, Cho, \& Dolecek, 2007). Also, asking questions about smoking in a neutral way and giving respondents a choice between multiple answers increases the likelihood of obtaining correct answers (Lindqvist, Lendahls, Tollbom, Aberg, \& Hakansson, 2002). In this study, Pearson's correlation coefficient between self-reported smoking status of the respondents and smoking status according to CO level was significant $(r=.993, p<.001)$. Therefore, it may be assumed that the answers regarding smoking status are reliable.

\section{Measurements}

The following data were collected through self-reporting: smoking behavior of the participant and her partner, feelings of depression, and sociodemographic variables (age, educational level, job status, gravidity, and marital status).

Smoking At every time point, respondents were asked to provide details about their previous and current smoking status, daily consumption, and duration of abstinence in the case of successful quitting. On the basis of answers at the three data collection points and taking into account the results of the CO measurement, respondents were categorized as follows:

1. smokers: respondents who reported to be smoking at all time points;

2. nonsmokers: respondents who never smoked or had quit for longer than 1 year before T0 - they reported to be nonsmoker at all time points;

3. recent ex-smokers: respondents who quit less than 1 year before $\mathrm{T} 0$ - they reported to be abstinent at all time points;

4. initial smokers: respondents with a variable smoking pattern who reported to be smoking at T0 and made a quit attempt;

5. initial nonsmokers: respondents with a variable smoking pattern who reported to be a nonsmoker at T0, but relapsed at $\mathrm{T} 1$ or $\mathrm{T} 2$.

The partners' smoking status (if applicable) was asked and categorized as "smoking" or "nonsmoking."

Feelings of Depression The Dutch version of the Beck Depression Inventory (BDI; Beck, Rush, Shaw, \& Emery, 1979) was used to assess the self-reported degree of depression (Demyttenaere \& De Fruyt, 2003). This inventory examines an individual's emotional condition in the week prior to assessment and is well suited for use in a primary care setting, both as a rapid screening test for depression during pregnancy (Bennett et al., 2004) and as a longitudinal assessment for depression (Marcus \& Heringhausen, 2009). It measures 21 emotional, behavioral, and somatic symptoms, which are each rated from 0 to 3 (Beck et. al., 1979). A score of 9 or less is considered normal, a score of 10-14 suggests a mild mood disturbance, and a score of 15 has been suggested as an indicator for clinical depression. Higher scores indicate an increasing severity of depression (Milgrom et al., 2011).

The BDI was preferred to the Edinburgh Postnatal Depression Scale. The BDI is internationally recognized and is available in a validated Dutch version. Research shows that both scales, BDI and Edinburgh Postnatal Depression Scale, 
are highly predictive in identifying depressive disorders during pregnancy and postpartum (Ji et al., 2011).

Sociodemographic Variables The questionnaire included the following variables: age, educational level, job status, and gravidity. Age was coded into two levels: $<29$ years (mean of the sample) and $\geq 29$ years. Respondents were asked for the highest grade or year of school completed. The education variable was coded into two levels: secondary school certificate or lower, meaning 12 years of education or less, or college or university degree. Unemployed women and housewives were classified as not having a paid job; working women and women on maternity leave were classified as having a paid job. Gravidity was coded into primigravida (pregnant for the first time) or multigravida.

\section{Data Analysis}

Data were analyzed using SAS software, version 9.2 (SAS Institute, Inc., Cary, NC). Respondent characteristics were examined using means and standard deviations for age and percentages for categorical variables (educational level, job status, gravidity, and smoking status of the partner).

The effect on the BDI of smoking pattern, time point, smoking status of the partner, educational level, gravidity, job status, and age was examined with linear mixed models (PROC MIXED: normal distribution and identity link function). Respondent number was considered a random effect, and suc- cessive BDIs within the same respondent were considered a repeated measure. A first-order autoregressive variance covariance matrix was included to take into account the dependency of successive BDI scores within the same person. The modeling procedure started with the univariate analyses. Variables with a $p<.25$ in the univariate analyses were included in the multivariable analysis. Gravidity and job status were not considered in the multivariable analysis because they were associated with age and educational level, respectively. Nonsignificant main effects in the multivariable analysis were eliminated one by one starting with the main effect with the highest $p$ value. Only when significant main effects $(p<.05)$ remained in the model, interactions (two-way and higher-order interactions) of the main effects were included in the model. A backward elimination procedure was conducted again starting with the highest-order interaction term. At all times, residual plots were used to evaluate the model fit.

\section{Results}

\section{Characteristics of Respondents}

Initially 627 women were recruited. Of these, 21 gave informed consent but could not subsequently be reached (one woman was expecting twins and was excluded). Eventually, 605 respondents were contacted at T0. Several respondents were excluded because of missing values. Finally, 523 respondents were included, whereas 82 respondents $(13.56 \%)$ were lost to follow-up. Table 1 gives an overview of the distribution of

TABLE I. Characteristics of the Respondents

\begin{tabular}{|c|c|c|c|c|c|}
\hline Characteristic & $\begin{array}{l}\text { Smokers } \\
(n=30)\end{array}$ & $\begin{array}{l}\text { Recent Ex-smokers } \\
\qquad(n=53)\end{array}$ & $\begin{array}{l}\text { Nonsmokers } \\
\quad(=416)\end{array}$ & $\begin{array}{l}\text { Initial Smokers } \\
\quad(n=14)\end{array}$ & $\begin{array}{l}\text { Initial Nonsmokers } \\
\qquad(n=10)\end{array}$ \\
\hline \multicolumn{6}{|l|}{ Age } \\
\hline Mean $(S D)$ & $30.1(4.98)$ & $27.2(4.6)$ & $29.2(4.1)$ & $26.6(4.7)$ & $28.2(1.9)$ \\
\hline Range & $23-45$ & $18-41$ & $18-45$ & 21-36 & $26-32$ \\
\hline \multicolumn{6}{|l|}{ Education, $n(\%)$} \\
\hline Secondary school certificate or less & $22(73.3)$ & $43(81.1)$ & $104(25.0)$ & $7(50.0)$ & $3(30.0)$ \\
\hline College or university degree & $8(26.7)$ & $10(18.9)$ & $312(75.0)$ & $7(50.0)$ & $7(70.0)$ \\
\hline \multicolumn{6}{|l|}{ Job status, $n(\%)$} \\
\hline Paid job & $27(90.0)$ & $40(75.5)$ & $396(95.2)$ & $10(71.4)$ & $10(100.0)$ \\
\hline No paid job & $3(10.0)$ & $13(24.5)$ & $19(4.6)$ & $4(28.6)$ & $0(0.0)$ \\
\hline Missing & & & $1(0.2)$ & & \\
\hline \multicolumn{6}{|l|}{ Gravidity, $n(\%)$} \\
\hline 1 & $17(56.7)$ & 17 (32.1) & $172(41.3)$ & $11(78.6)$ & $5(50.0)$ \\
\hline 2 & $7(23.3)$ & $22(41.5)$ & $148(35.6)$ & $2(14.3)$ & $2(20.0)$ \\
\hline 3 & $3(10.0)$ & $8(15.1)$ & $59(14.2)$ & $3(7.1)$ & $3(30.0)$ \\
\hline 4 & $1(3.3)$ & $3(5.7)$ & $29(7.0)$ & & \\
\hline$\geq 5$ & $2(6.6)$ & $3(5.7)$ & $8(1.9)$ & & \\
\hline \multicolumn{6}{|l|}{ Partner, $n(\%)$} \\
\hline Smoking partner & $12(40.0)$ & $38(71.1)$ & 76 (18.3) & $10(71.4)$ & $4(40.0)$ \\
\hline Nonsmoking partner & $15(50.0)$ & $12(22.6)$ & $334(80.4)$ & $3(21.4)$ & $5(50.0)$ \\
\hline Missing & $3(10.0)$ & $3(6.3)$ & $6(1.3)$ & $1(7.2)$ & $1(10.0)$ \\
\hline
\end{tabular}

Note. Percentages are calculated within the smoking pattern. 
the demographic variables (age, educational level, job status, gravidity, and smoking status of the partner) according to the smoking pattern. The mean age of respondents was 29 years (range, $17-45$ years; $S D=4.38$ years). Of the partners, 369 $(70.6 \%)$ were nonsmokers, and $140(26.77 \%)$ were smokers. Only $18.3 \%$ of the nonsmoking women had a smoking partner, whereas more than $70 \%$ of recent ex-smokers and initial smokers had a smoking partner. In the smokers group, $40 \%$ had a smoking partner.

\section{Patterns of Smoking During and After Pregnancy}

On the basis of answers at the three data collection points and taking into account the results of the $\mathrm{CO}$ measurement, respondents were categorized in five smoking patterns: smokers, nonsmokers, recent ex-smoker, initial smokers, and initial nonsmokers (Table 2). Respondents with missing values regarding their smoking pattern at T1 and T2 were excluded. Smokers and recent ex-smokers with a missing value regarding their smoking pattern at $\mathrm{T} 1$ or $\mathrm{T} 2$ were also excluded. Respondents of the nonsmokers group were assumed to be nonsmokers at all time points and were included. Finally, 523 respondents were included, whereas 82 respondents $(13.56 \%)$ were lost to follow-up. To assess the effect of attrition, the BDI at T0 was compared between the respondents from which information on the smoking status was available at T1 and T2 and those from which information was missing at T1 and/or T2. The BDI at T0 was not statistically significantly different $(p=0.2807)$ between those included and excluded.

TABLE 2. Overview of Smoking Patterns, Number of Respondents Included, and Attrition

\begin{tabular}{|c|c|c|c|c|c|c|}
\hline Smoking pattern & TO & $\mathrm{T} 1$ & $\mathrm{~T} 2$ & Explanation & $n$ & Attrition \\
\hline \multirow[t]{2}{*}{ Smokers } & Smoker & Smoker & Smoker & Persistent smokers & 53 & $\begin{array}{l}\text { Missing } \mathrm{T} 1=1 \\
\text { Missing } \mathrm{T} 2=18 \\
\text { Missing } \mathrm{T} 1 \text { and } \mathrm{T} 2=16\end{array}$ \\
\hline & & & & & 53 & 35 \\
\hline \multirow[t]{9}{*}{ Nonsmokers } & Nonsmoker & Nonsmoker & Nonsmoker & $\begin{array}{l}\text { Respondents who never } \\
\text { smoked }\end{array}$ & 232 & Missing $\mathrm{T} 1$ and $\mathrm{T} 2=23$ \\
\hline & & & & OR & Missing $\mathrm{T} 1=23$ & \\
\hline & & & & & Missing $\mathrm{T} 2=40$ & \\
\hline & & & & & $232+23+40=295$ & \\
\hline & Nonsmoker & Nonsmoker & Nonsmoker & $\begin{array}{l}\text { Quit more than } 1 \text { year } \\
\text { prior to data collection }\end{array}$ & 108 & Missing $\mathrm{T} 1$ and $\mathrm{T} 2=9$ \\
\hline & & & & & Missing $T 1=1$ & \\
\hline & & & & & Missing $\mathrm{T} 2=12$ & \\
\hline & & & & & $108+1+12=121$ & \\
\hline & & & & & 416 & 32 \\
\hline \multirow[t]{4}{*}{ Recent ex-smokers } & Nonsmoker & Nonsmoker & Nonsmoker & $\begin{array}{l}\text { Nonsmoker who reported having } \\
\text { quit within the year prior to TO }\end{array}$ & 30 & Missing $\mathrm{T} 1=0$ \\
\hline & & & & & & Missing T2 = 10 \\
\hline & & & & & & Missing $\mathrm{T} 1$ and $\mathrm{T} 2=5$ \\
\hline & & & & & 30 & 15 \\
\hline \multirow[t]{4}{*}{$\begin{array}{l}\text { Variable pattern: } \\
\text { initial smokers }\end{array}$} & Smoker & Smoker & Nonsmoker & $\begin{array}{l}\text { Quit after } 34 \text { weeks of pregnancy } \\
\text { or in postpartum }\end{array}$ & 3 & \\
\hline & Smoker & Nonsmoker & Smoker & $\begin{array}{l}\text { Quit during pregnancy, even } \\
\text { though they later resumed }\end{array}$ & 3 & \\
\hline & Smoker & Nonsmoker & Nonsmoker & Quit early in pregnancy & 8 & \\
\hline & & & & & 14 & 0 \\
\hline \multirow{5}{*}{$\begin{array}{l}\text { Variable pattern: } \\
\text { initial nonsmokers }\end{array}$} & Nonsmoker & Smoker & Nonsmoker & Intermittent smoking pattern & 1 & \\
\hline & Nonsmoker & Smoker & Smoker & Started again during pregnancy & 3 & \\
\hline & Nonsmoker & Nonsmoker & Smoker & $\begin{array}{l}\text { Started again after the baby } \\
\text { was born }\end{array}$ & 6 & \\
\hline & & & & & 10 & 0 \\
\hline & & & & Total & 523 & 82 \\
\hline
\end{tabular}

Note. $\mathrm{T} 0=$ Prior to 16 weeks gestation; $\mathrm{T} 1=32-34$ weeks gestation; $\mathrm{T} 3=$ after 6 weeks postpartum . 


\section{Patterns of Depression During and After Pregnancy}

Table 3 shows the mean BDI score according to the smoking pattern during and after pregnancy. At all time points, the mean BDI score of recent ex-smokers, nonsmokers, and initial nonsmokers was normal $(<10)$. Smokers and initial smokers showed an elevated mean BDI score $(\geq 10)$ during pregnancy. After pregnancy, their BDI score normalized.

\section{Relationships Among BDI Score, Smoking} Pattern, and Sociodemographic Variables The results of the univariate analysis are shown in Table 4. At all sampling points (T0, T1, and T2), smokers and initial smokers reported significantly more depressive symptoms compared with recent ex-smokers, nonsmokers, and initial nonsmokers $(p<.001)$.

Women with a secondary school certificate or less reported a significantly higher BDI score than higher educated women $(p<.0001)$. Women without a paid job had a significantly higher BDI score compared with women with a job $(p=.01)$. The BDI score was significantly lower after delivery $(p<$ $.0001)$. Having a smoking partner resulted in a significantly higher score on the BDI scale $(p<.02)$. Women younger than

TABLE 3. BDI Scores Over Time by Smoking Pattern

\begin{tabular}{|c|c|c|c|c|}
\hline \multirow[b]{2}{*}{ Pattern } & \multirow[b]{2}{*}{ Statistic $^{a}$} & \multicolumn{3}{|c|}{ Time of measurement } \\
\hline & & TO & $\mathrm{T} 1$ & T2 \\
\hline \multirow[t]{3}{*}{ Smokers } & $M$ & 11.17 & 11.28 & 9.61 \\
\hline & $S D$ & 7.00 & 7.95 & 7.15 \\
\hline & Range & $0-36$ & $0-42$ & $0-31$ \\
\hline \multirow[t]{3}{*}{ Nonsmokers } & $M$ & 6.95 & 7.02 & 5.29 \\
\hline & $S D$ & 4.75 & 4.48 & 3.86 \\
\hline & Range & $0-29$ & $0-33$ & $0-21$ \\
\hline \multirow[t]{3}{*}{ Recent ex-smokers } & $M$ & 6.09 & 7.45 & 4.22 \\
\hline & $S D$ & 5.33 & 7.11 & 3.70 \\
\hline & Range & $0-24$ & $0-31$ & $0-13$ \\
\hline \multirow[t]{3}{*}{ Nonsmokers } & $M$ & 6.95 & 7.02 & 5.29 \\
\hline & $S D$ & 4.75 & 4.48 & 3.86 \\
\hline & Range & $0-29$ & $0-33$ & $0-21$ \\
\hline \multirow[t]{3}{*}{ Initial smokers } & $M$ & 10.77 & 12.33 & 7.69 \\
\hline & $S D$ & 5.16 & 5.16 & 4.80 \\
\hline & Range & $3-19$ & $4-19$ & $0-18$ \\
\hline \multirow[t]{3}{*}{ Initial nonsmokers } & $M$ & 7.71 & 6.00 & 5.56 \\
\hline & $S D$ & 3.04 & 2.07 & 3.75 \\
\hline & Range & $3-13$ & $3-10$ & $1-13$ \\
\hline
\end{tabular}

Note. $\mathrm{T0}=$ Prior to 16 weeks gestation; $\mathrm{T} 1=32-34$ weeks gestation; $\mathrm{T} 3=$ after 6 weeks postpartum; BDI = Beck Depression Inventory. ${ }^{\text {a }}$ Statistics are for BDI total scores.
29 years (mean of the sample) had a significantly higher BDI score $(p<.008)$. There was no significant difference in BDI score between primigravidas and multigravidas $(p<.06)$.

The results of the multivariable analysis are shown in Table 5 and Figure 1.

All main effects in the final model were significant (Table 5). The two-way interaction between smoking pattern and time point was not significant $(p<.15)$. The two-way interaction between educational level and smoking pattern was also not significant $(p=$ .30). There were however significant differences in reported BDI within the educational level between the smoking patterns. Smokers with a secondary school certificate or less scored significantly higher on the BDI compared with their nonsmoking counterparts $(p=$ $.05)$. Initial smokers with a college or university degree scored significantly higher on the BDI scale compared with nonsmokers and recent ex-smokers with a college or university degree. We found in respondents with a college or university degree no significant difference in BDI score between smokers, recent ex-smokers, and nonsmokers.

The two-way interaction between educational level and time point was significant $(p<.009)$. The pattern of the BDI score was significantly different in time between respondents with a low or high education. In women with a secondary school certificate or less, the mean BDI decreased in time ( T0 $=9.62, \mathrm{~T} 1=8.72, \mathrm{~T} 2=8.25)$. In women with a college or university degree, the highest score was found at the end of pregnancy, the lowest in postpartum $(\mathrm{T} 0=7.29$, $\mathrm{T} 1=8.49$, $\mathrm{T} 2=4.98$ ).

The three-way interaction between time point, smoking pattern, and educational level was significant $(p=.02$; Figure 1 ). Significant differences $(p<.05)$ of the evolution of the mean BDI over time was assessed pair wise between smoking pattern classes within educational level class and between the educational level classes of each smoking pattern class. The evolution of the mean BDI over time differed between the educational level classes of smokers. Within respondents with a secondary school certificate or less, differences were observed between smokers and nonsmokers, recent ex-smokers and initial nonsmokers, and nonsmokers and initial nonsmokers. Within the respondents with a college or university degree, no differences were observed.

\section{Discussion}

The aim of this longitudinal study was to obtain a better insight into the possible association between smoking patterns and depressive feelings during pregnancy and postpartum, taking into account several sociodemographic characteristics. The longitudinal design is a strength of this study: Respondents were questioned three times. This made it possible to examine mood fluctuations and changes in smoking pattern both during pregnancy and postpartum.

Most importantly, recent ex-smokers reported fewer feelings of depression compared with smokers and initial smokers during pregnancy and postpartum, confirming the results of 
recent research that showed decreasing feelings of depression in the case of successful quitting (Berlin et al., 2010; Kahler et al., 2011). Smoking, as well as depression, can result in preterm birth and low birth weight; the combination of both risk factors might aggravate these complications (Bull, 2007; Goedhart, van der Wal, Cuijpers, \& Bonsel, 2009; Grote et al., 2010). This emphasizes the fact that both smoking cessation and feelings of depression should be addressed during prenatal consultations.

Second, smokers with a secondary school certificate or less reported a mean BDI score of 10.89 , which indicates that they experienced moderate feelings of dysphoria during and after pregnancy. However, this score is lower than the clinical depression indicator of 15 . The increased BDI scores at all time points in lower educated smoking women, as illustrated in Figure 1A, might be explained by the meanings smoking has for these women - smoking might be a way of dealing with negative feelings or experiences (e.g., problems related to altered life circumstances because of motherhood, feelings of failure because of lack of a paid job, financial problems, problems of accommodation, a problematic relationship, or a lack of support from their partner). Further investigation is needed to identify these meanings of smoking.

Low socioeconomic status, including lower educational level and job status, and depression, have been shown to be independent risk factors leading to persistent smoking during pregnancy (Zhu \& Valbo, 2002; Solomon et al., 2006). The findings on BDI score and educational level are in line with these studies, but go further in showing that feelings of depression remain significant during the entire pregnancy and in postpartum. This finding is important for smoking cessation interventions in lower educated pregnant women and new mothers. Thus, smoking cessation might be hampered by depressive symptoms, and interventions that treat dysphoria and depression may facilitate smoking cessation (Cinciripini et al., 2010).

Respondents with a variable smoking pattern showed mixed results. It is remarkable that the high educated initial smokers showed an elevated BDI score compared with their

TABLE 4. BDI: Univariate Analysis

BDI

\begin{tabular}{|c|c|c|c|c|}
\hline \multirow[b]{2}{*}{ Variable } & & \multirow[b]{2}{*}{$F\left(d f_{\text {num }}, d f_{\text {denum }}\right)$} & \multirow[b]{2}{*}{$p$} \\
\hline & $M$ & $(S E)$ & & \\
\hline Smoking pattern & & & $12.06(4,486)$ & $<.001$ \\
\hline Smokers & $10.16^{b}$ & $(0.57)$ & & \\
\hline Nonsmokers & $6.42^{\mathrm{a}}$ & $(0.20)$ & & \\
\hline Recent ex-smokers & $5.56^{\mathrm{a}}$ & $(0.77)$ & & \\
\hline Initial smokers & $9.83^{b}$ & $(1.10)$ & & \\
\hline Initial nonsmokers & $6.23^{a, b}$ & $(1.40)$ & & \\
\hline Educational level & & & $40.39(1,496)$ & $<.0001$ \\
\hline Secondary school certificate or less & $8.52^{\mathrm{a}}$ & $(0.32)$ & & \\
\hline College or university degree & $6.06^{\mathrm{b}}$ & $(0.22)$ & & \\
\hline Job status & & & $6.14(1,489)$ & .01 \\
\hline Paid job & $6.70^{\mathrm{a}}$ & $(0.19)$ & & \\
\hline No paid job & $8.50^{\mathrm{b}}$ & $(0.70)$ & & \\
\hline Time point & & & $40.15(2,643)$ & $<.0001$ \\
\hline TO & $7.35^{\mathrm{a}}$ & $(0.22)$ & & \\
\hline $\mathrm{T} 1$ & $7.54^{\mathrm{a}}$ & $(0.23)$ & & \\
\hline $\mathrm{T} 2$ & $5.68^{\mathrm{b}}$ & $(0.23)$ & & \\
\hline Smoking behavior of the partner & & & $5.37(1,495)$ & .021 \\
\hline Smoking partner & $7.51^{\mathrm{a}}$ & $(0.35)$ & & \\
\hline Nonsmoking partner & $6.55^{\mathrm{b}}$ & $(0.22)$ & & \\
\hline Gravidity & & & $3.49(1,496)$ & .06 \\
\hline Primigravida & 6.41 & $(0.29)$ & & \\
\hline Multigravida & 7.12 & $(0.24)$ & & \\
\hline Age & & & $7.11(1,495)$ & .008 \\
\hline$<29$ years & $7.34^{\mathrm{a}}$ & $(0.27)$ & & \\
\hline$\geq 29$ years & $6.35^{\mathrm{b}}$ & $(0.26)$ & & \\
\hline
\end{tabular}

Note. Values with a different superscript within a variable differ significantly from one another (Bonferroni corrected $p<.05$ ). BDI $=$ Beck Depression Inventory. 


\section{TABLE 5. Multivariate Analysis}

BDI

\begin{tabular}{lcc}
\cline { 3 - 3 } Variables & $\mathbf{M}$ & (SE $)$ \\
\hline Main effects & & \\
Smoking pattern & & \\
Smokers & $9.19^{\mathrm{a}}$ & $(0.71)$ \\
Nonsmokers & $6.82^{\mathrm{b}}$ & $(0.22)$ \\
Recent ex-smokers & $6.41^{\mathrm{a}, \mathrm{b}}$ & $(0.83)$ \\
Initial smokers & $10.0^{\mathrm{a}}$ & $(1.09)$ \\
Initial nonsmokers & $7.03^{\mathrm{a}, \mathrm{b}}$ & $(1.58)$ \\
Educational level & & \\
Secondary school certificate or less & $8.86^{\mathrm{a}}$ & $(0.71)$ \\
College or university degree & $6.91^{\mathrm{b}}$ & $(0.54)$ \\
Time point & & \\
T0 & $8.46^{\mathrm{a}}$ & $(0.55)$ \\
T1 & $8.60^{\mathrm{a}}$ & $(0.55)$ \\
T2 & $6.61^{\mathrm{b}}$ & $(0.54)$ \\
\end{tabular}

$1.51(8,619)$

Smoking pattern ${ }^{\star}$ time point

Educational level ${ }^{*}$ smoking pattern ${ }^{c}$

Secondary school certificate or less

\section{Smokers}

Nonsmokers

Recent ex-smokers

Initial smokers

Initial nonsmokers

College or university degree

Smokers

Nonsmokers

Recent ex-smokers

Initial smokers

Initial nonsmokers

Educational level ${ }^{*}$ time point ${ }^{c}$

Secondary school certificate or less

$\begin{array}{ll}\text { T0 } & 9.62^{\mathrm{a}} \\ \text { T1 } & 8.72^{\mathrm{a}} \\ \text { T2 } & 8.25^{\mathrm{a}} \\ \text { College or university degree } & \\ \text { T0 } & 7.29^{\mathrm{a}} \\ \text { T1 } & 8.49^{\mathrm{a}} \\ \text { T2 } & 4.98^{\mathrm{b}}\end{array}$

$10.89^{\mathrm{a}}$

$7.60^{\mathrm{b}}$

$6.41^{\mathrm{a}, \mathrm{b}}$

$9.18^{a, b}$

$8.67^{\mathrm{a}, \mathrm{b}}$

$7.48^{\mathrm{a}, \mathrm{b}}$

$6.04^{\mathrm{a}}$

$6.41^{\mathrm{a}, \mathrm{b}}$

$10.83^{\mathrm{b}}$

$5.40^{\mathrm{a}, \mathrm{b}}$

$9.62^{\mathrm{a}}$

$8.72^{\mathrm{a}}$

$8.25^{\mathrm{a}}$

$7.29^{\mathrm{a}}$

$8.49^{\mathrm{a}}$

$4.98^{\mathrm{b}}$
$4.77(2,594)$

(0.65)

Time point ${ }^{\star}$ smoking pattern ${ }^{*}$ educational level ${ }^{d}$

Note. Values with a different superscript $(a, b)$ within a variable differ significantly from one another (Bonferroni corrected $p<.05)$. ${ }^{\circ}$ Superscripts refer to within classes of educational level. ${ }^{d}$ See Figure $1 . \mathrm{BDI}=$ Beck Depression Inventory.

low educated counterparts (Figure 1B). This could suggest that their experiences with smoking cessation were more negative or that they experienced other problems at that time point. At
T2, the mean BDI score normalized both in low and high educated respondents (8.03 and 7.86, respectively). Partners are major amplifiers of smoking behavior, both positive and 


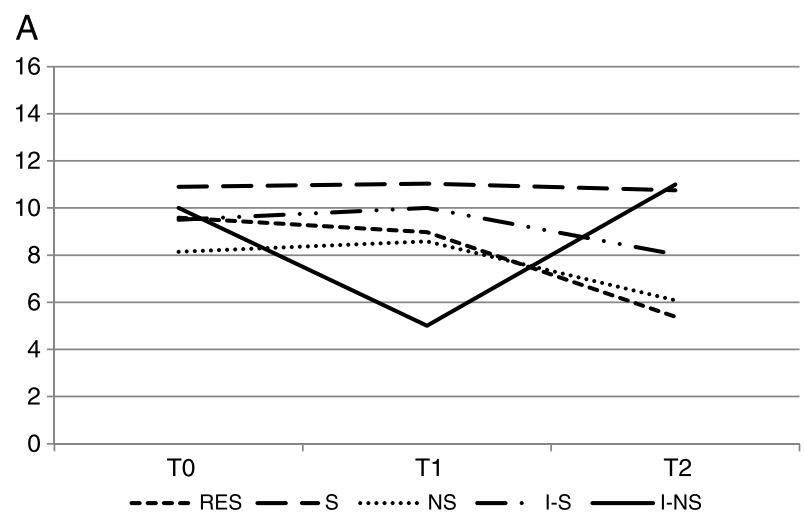

B

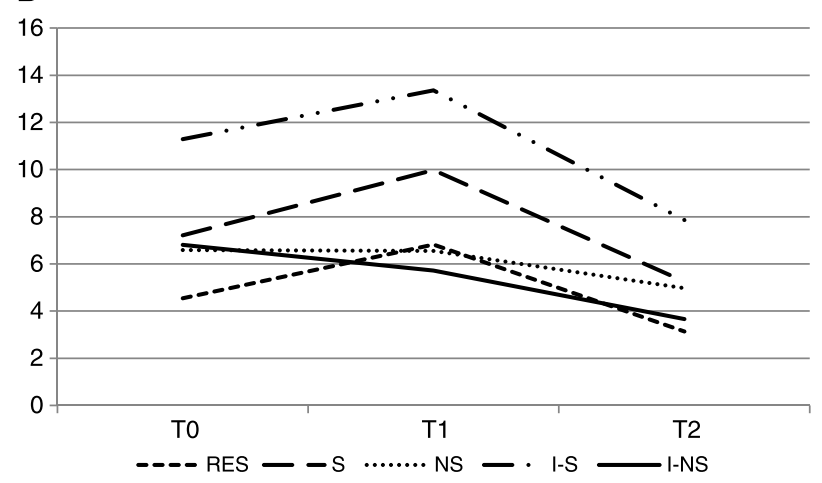

FIGURE 1. Mean BDI in recent ex-smokers (RES), smokers (S), nonsmokers (NS), initial smokers (I-S), and initial nonsmokers (I-NS) at successive time points (T0, T1, and T2). Respondents with a secondary school certificate or less are shown in (A) and respondents with a college or university degree are shown in (B).

negative, and are key contributors toward the success or failure of the women's smoking cessation efforts (Hauge et al., 2012; Schneider et al., 2010). In this study recent ex-smokers and initial smokers had the highest percentage of smoking partners $(71.1 \%$ and $71.4 \%$, respectively). This means that women who recently attempted quitting are more at risk for relapse and that their partner should be involved in smoking cessation counseling.

The recorded relapse rate of smoking was low (T1: four respondents in the initial nonsmokers group, T2: three respondents of the initial smokers and six of the initial nonsmokers), but it is possible that more recent ex-smokers relapsed and subsequently refused further participation in the study. Of the original 45 respondents in this group, 15 respondents were excluded because of attrition. However, it can be assumed that women who admitted being a smoker provided the correct information regarding their smoking behavior, given the negative societal bias against pregnancy and smoking.

A possible limitation to this study is the relatively high dropout rate of $13.56 \%$, partially because of our own strict exclusion criteria for smokers $(39.8 \%)$ and recent ex-smokers $(33.3 \%)$. If there were any missing values regarding their smoking behavior at T1 or T2, the respondents were excluded. In nonsmokers, the dropout rate was $7.1 \%$. Consequently, some of the groups are rather small. The high level of dropout might be explained by the lack of benefits associated with participation, resulting in a lower commitment to complete the sur- vey at T1 and T2 (Crittenden et al., 2007). It is also known that a telephone survey in longitudinal research has a higher dropout rate than face-to-face contact, especially in respondents of low socioeconomic status because of inconsistent telephone availability (Biener, Hamilton, Siegel, \& Sullivan, 2010; Crittenden et al., 2007). Smokers, especially smokers with a lower socioeconomic status, participate less easily in scientific research and dropout more often than nonsmokers (Crittenden et al., 2007). In this study, the dropout percentage was comparable with other research, which reported a dropout of $43 \%$ in smokers and ex-smokers over a period of 1 year (Biener et al., 2010).

It can be concluded that recent ex-smokers reported less symptoms of depression compared with smokers and initial smokers, independent of their educational level, suggesting that smoking cessation shortly before or in early pregnancy does not aggravate depressive symptoms during pregnancy and in postpartum. Mean BDI scores decreased in postpartum, except in low educated smokers, where BDI scores remained constantly above 10 during pregnancy and postpartum, suggesting that smoking could be a way of coping with difficult life conditions.

In case of a presumption of feelings of depression, healthcare providers could consider measuring the level of depression in pregnant women, for example, by using the BDI. In case of a score of $\geq 15$, not only referral to a specialized smoking cessation consultation could be considered but also specialized therapy treating depression.

Given the relationship between smoking, low educational level, and depression established in this study, it is suggested that professionals should take enough time to explore not only obstetric parameters but also the lifestyle of the pregnant woman during a first consultation. A history should include questions about educational level, job status, and smoking habits of the woman and, if appropriate, of the partner. Specific attention should be paid to feelings of depression in women with a lower educational level, not only during pregnancy when there are more contacts with healthcare workers but also during postpartum when contacts are fewer. Smoking cessation advice and the detection and treatment of depression during pregnancy can prevent the occurrence of more severe health problems in new mothers and babies. It is important to identify those women who may need more specialized care and that smoking cessation counseling is tailored to their needs and possibilities, paying attention to an appropriate methodology (e.g., using appropriate language and didactical tools). If possible, the partner should also be involved in the consultation.

Further studies should address and examine the impact of partner support in smoking cessation and relapse prevention, especially in low educated couples and recent ex-smokers, and identify the meanings smoking has in low educated women.

\section{Conclusion}

A wide variety of smoking patterns were observed during pregnancy and the early postpartum. Smoking patterns were associated with depression and showed complex interactions with educational level. Assessment and intervention for both smoking and depression are needed throughout the perinatal period to support the health of mothers, their infants, and families. 


\section{Accepted for publication June 24, 2013.}

The authors would like to thank Kathleen Temmerman, MSc, Vera Balduyck, $M S c$, Marc Coenen, MD, Head of the Department of Gynecology-Obstetrics, AZ Nikolaas, Ellen Smolders, RM, all gynecologists and midwives of the Prenatal Consultation Unit of the University Hospital Ghent, participating gynecologists, and independent midwives for their administrative, technical, and material support.

This research was supported in part by grants from the Flemish Government and the Catholic University College Ghent.

The authors have no conflicts of interest to report.

Corresponding author: Katrien De Wilde, MSc, Doctoral candidate, College Ghent, Department of Health, Catholic University, Hospitaalstraat 23, 9100 Sint-Niklaas, Belgium (e-mail: katrien.dewilde@kahosl.be).

\section{References}

Beck, A. T., Rush, A. J., Shaw, B. F., \& Emery, G. (1979). Cognitive therapy of depression. New York, NY: Guilford Press.

Beck, C. T. (2001). Predictors of postpartum depression, an update. Nursing Research, 50, 275-285.

Bennett, H. A., Einarson, A., Taddio, A., Koren, G., \& Einarson, T. R. (2004). Prevalence of depression during pregnancy: Systematic review. Obstetrics \& Gynecology, 103, 698-709.

Benowitz, N. L., Jacob, P., Ahijevych, K., Jarvis M. J., Hall, S., LeHouezec, J., ... Velicer, W. (2002). Biochemical verification of tobacco use and cessation. Nicotine and Tobacco Research, 4, 149-159.

Berlin, I., Chen, H., \& Covey, L. S. (2010). Depression mood, suicide ideation and anxiety in smokers who do and smokers who do not manage to stop smoking after a target quit day. Addiction, 105, 2209-2216.

Biener, L., Hamilton, W. L., Siegel, M., \& Sullivan, E. M. (2010). Individual, social- normative, and policy predictors of smoking cessation: A multilevel longitudinal analysis. American Journal of Public Health, 100, 547-554.

Bull, L. (2007). Smoking intervention with pregnant women and new parents (part 2): A focus group study of health visitors and midwives working in the UK. Journal of Neonatal Nursing, 13, 179-185.

Cinciripini, P. M., Blalock, J. A., Minnix, J. A., Robinson, J. D., Brown, V. L., Lam, C., ... Karam-Hage, M. (2010). Effects of an intensive depression-focused intervention for smoking cessation in pregnancy. Journal of Consulting and Clinical Psychology, 78, 44-54.

Christensen, A. E., Tobiassen, M., Jensen, T. K., Wielandt, H., Bakketeig, L., \& Høst, A. (2004). Repeated validation of parental self-reported smoking during pregnancy and infancy: A prospective cohort study of infants at high risk for allergy development. Paediatric and Perinatal Epidemiology, 18, 73-79.

Crittenden, K. S., Manfredi, C., Cho, Y. I., \& Dolecek, T. A. (2007). Smoking cessation processes in low-SES women: The impact of time-varying pregnancy status, health care messages, stress, and health concerns. Addictive Behaviors, 32, 1347-1366.

Demyttenaere, K., \& De Fruyt, J. (2003). Getting what you ask for: On the selectivity of depression rating scales. Psychotherapy and Psychosomatics, 72, 61-70.

Edwards, B., Galletly, C., Semmler-Booth, T., \& Dekker, G. (2008). Does antenatal screening for psychosocial risk factors predict postnatal depression? A follow-up study of 154 women in Adelaide, South Australia. Australian and New Zealand Journal of Psychiatry, 42, 51-55.

Emmanuel, E., \& St John, W. (2010). Maternal distress: A concept analysis. Journal of Advanced Nursing, 66, 2104-2115.

Goedhart, G., van der Wal, M. F., Cuijpers, P., \& Bonsel, G. J. (2009). Psychosocial problems and continued smoking during pregnancy. Addictive Behaviors, 34, 403-406.

Grote, N. K., Bridge, J. A., Gavin, A. R., Melville, J. L., Iyengar, S., \& Katon, W. J. (2010). A meta-analysis of depression during preg- nancy and the risk of preterm birth, low birth weight, and intrauterine growth restriction. Archives of General Psychiatry, 67, 1012-1024.

Hauge, L. J., Torgersen, L., \& Vollrath, M. (2012). Associations between maternal stress and smoking: Findings from a populationbased prospective cohort study. Addiction, 107, 1168-1173.

Higgins, S. T., Heil, S. H., Badger, G. J., Mongeon, J. A., Solomon, L. J., McHale, L., \& Bernstein, I. M. (2007). Biochemical verification of smoking status in pregnant and recently postpartum women. Experimental and Clinical Psychopharmacology, 15, 58-66.

Higgins, S. T., Heil, S. H., Badger, G. J., Skelly, J. M., Solomon, L. J., \& Bernstein, I. M. (2009). Educational disadvantage and cigarette smoking during pregnancy. Drug and Alcohol Dependence, 104, S100-S105.

Hoppenbrouwers, K., Roelants, M., Guérin, C., Van Leeuwen, K., Desoete, A., \& Wiersema, J. R. (2011). Als mama rookt, rookt baby mee. Sociaaleconomische indicatoren en perinatale gezondheidseffecten van gedwongen blootstelling van een Vlaamse geboortecohorte aan tabaksrook tijdens de zwangerschap en in de eerste levensweken (in samenwerking met Kind en Gezin) [If mommy smokes, the baby also smokes. Socio-economic indicators and perinatal health effects of forced exposure to tobacco smoke during pregnancy and in the first weeks of life in a Flemish birth cohort (in cooperation with the organization "Child and Family")]. Steunpunt Welzijn, Volksgezondheid en Gezin, Feiten, \& Cijfers, 2011-2017.

Ji, S., Long, Q., Newport, D. J., Na, H., Knight, B., Zach, E. B., ... Stowe, Z. N. (2011). Validity of depression rating scales during pregnancy and the postpartum period: Impact of trimester and parity. Journal of Psychiatric Research, 45, 213-219.

Kahler, C. W., Spillane, N. S., Busch, A. M., \& Leventhal, A. M. (2011). Time-varying smoking abstinence predicts lower depressive symptoms following smoking cessation treatment. Nicotine \& Tobacco Research, 13, 146-150.

Lancaster, C. A., Gold, K. J., Flynn, H. A., Yoo, H., Marcus, S. M., \& Davis, M. M. (2010). Risk factors for depressive symptoms during pregnancy: A systematic review. American Journal of Obstetrics and Gynecology, 202, 5-14.

Lauria, L., Lamberti, A., \& Grandolfo, M. (2011). Smoking behaviour before, during, and after pregnancy: The effect of breastfeeding. The Scientific World Journal, 2012, 1-9.

Leung, J., Gartner, C., Hall, W., Lucke, J., \& Dobson, A. (2012). A longitudinal study of the bidirectional relationship between tobacco smoking and psychological distress in a community sample of young Australian women. Psychological Medicine, 42, 1273-1282.

Levitt, C., Shaw, E., Wong, S., \& Kaczorowski, J. (2007). Systematic review of the literature on postpartum care: Effectiveness of interventions for smoking relapse prevention, cessation, and reduction in postpartum women. Birth, 34, 341-347.

Lindqvist, R., Lendahls, L., Tollbom, Ö., Aberg, H., \& Håkansson, A. (2002). Smoking during pregnancy: comparison of self-reports and cotinine levels in 496 women. Acta Obstetricia et Gynecologica Scandinavica, 81, 240-244.

Lumley, J., Chamberlain, C., Dowswell, T., Oliver, S., Oakley, L., \& Watson, L. (2009). Interventions for promoting smoking cessation during pregnancy (Review). Cochrane Database of Systematic Reviews, 8(3), CD001055.

Marcus, S. M., Flynn, H. A., Blow, F. C., \& Barry, K. L. (2003). Depressive symptoms among pregnant women screened in obstetrics settings. Journal of Women's Health, 12, 373-380.

Marcus, S. M., \& Heringhausen, J. E. (2009). Depression in childbearing women: When depression complicates pregnancy. Primary Care: Clinics in Office Practice, 36, 151-165.

McGowan, A., Hamilton, S., Barnett, D., Nsofor, M., Proudfoot, J., \& Tappin, D.M. (2010). "Breathe": The stop smoking service for pregnant women in Glasgow. Midwifery, 26, e1-e13.

Melville, J. L., Gavin, A., Guo, Y., Fan, M. Y., \& Katon, W. J. (2010). Depressive disorders during pregnancy-prevalence and risk 
factors in a large urban sample. Obstetrics and Gynecology, 116, 1064-1070.

Milgrom, J., Holt, C. J., Gemmill, A. W., Ericksen, J., Leigh, B., Buist, A., \& Schembri, C. (2011). Treating postnatal depressive symptoms in primary care: A randomised controlled trial of GP management, with and without adjunctive counselling. BMC Psychiatry, 11, 95.

Palma, S., Pérez-Iglesias, R., Pardo-Crespo, R., Llorca, J., Marisal, M., \& Delgado- Rodriguez, M. (2007). Smoking among pregnant women in Cantabria (Spain): Trend and determinants of smoking cessation. BMC Public Health, 7, 65.

Park, E. R., Chang, Y., Quinn, V., Regan, S., Cohen, L., Viguera, A., ... Rigotti, N. (2009). The association of depressive, anxiety, and stress symptoms and postpartum relapse to smoking: A longitudinal study. Nicotine \& Tobacco Research, 11, 707-714.

Pickett, K. E., Wilkinson, R. G., \& Wakschlag, L. S. (2009). The psychosocial context of pregnancy smoking and quitting in the Millenium Cohort Study. Journal of Epidemiology \& Community Health, 63, 474-480.
Scott, T. J., Heil, S. H., Higgins, S. T., Badger, G. J., \& Bernstein I. M. (2009). Depressive symptoms predict smoking status among pregnant women. Addictive Behaviors, 34, 705-708.

Secker-Walker, R. H., Vacek, P. M., Flynn, B. S., \& Meads, P. B. (1997). Exhaled carbon monoxide and urinary cotinine as measures of smoking in pregnancy. Addictive Behaviors, 22, 671-684.

Schneider, S., Huy, C., Schütz, J., \& Diehl, K. (2010). Smoking cessation during pregnancy: A systematic literature review. Drug and Alcohol Review, 29, 81-90.

Solomon, L. J., Higgins, S. T., Heil, S. H., Badger, G. J., Mongeon, J. A., \& Bernstein, I. M. (2006). Psychological symptoms following smoking cessation pregnant smokers. Journal of Behavioral Medicine, 29, 151-160.

Usmani, Z. C., Craig, P., Shipton, D., \& Tappin, D. (2008). Comparison of $\mathrm{CO}$ breath testing and women's self-reporting smoking behaviour for identifying smoking during pregnancy. Substance Abuse Treatment, Prevention, and Policy, 3, 4.

Zhu, S., \& Valbo, A. (2002). Depression and smoking during pregnancy. Addictive Behaviors, 27, 649-658. 